\title{
Perancangan Aplikasi E-Learning Berbasis Web dengan Model Prototype pada SMPN 7 Kota Tangerang Selatan
}

\author{
Mukhlishoh Syaukati Robbi ${ }^{1}$, Yulianti ${ }^{2}$ \\ ${ }^{1,2}$ Teknik Informatika, Universitas Pamulang, Tangerang Selatan, Banten, Indonesia \\ e-mail: ${ }^{1}$ mukhlishohsr@gmail.com, ${ }^{2}$ yulianti@unpam.ac.id
}

\begin{abstract}
Learning is the process of student interaction with educators and learning resources in a learning environment that includes teachers and students who exchange information. Therefore, learning must go well so that information can be delivered. Educators who are unable to attend will disrupt the delivery of learning material. Likewise, for students who are unable to attend will certainly miss the learning material provided by educators. With E-Learning making it easy in the process of teaching and learning activities in schools, teachers can provide materials and assignments anywhere, students are easy to get learning materials, and make it easy for students to do the assignments given by the teacher, without being hindered by the dimensions of space and time. The system development method used by the authors in conducting this research is the Prototype method. The Prototype method is prototyping software or life cycle using prototyping. One method of system life cycle is based on the concept of a working model. Where the system developer and client can see and conduct experiments since the beginning of the development process. In the Prototype method there are three stages (3) development cycle, namely: Requirement Collection Phase, Prototype Building Phase, and Trial Phase.
\end{abstract}

Keywords: Application; E-Learning; Material; Assignment; Prototype

\begin{abstract}
Abstrak
Pembelajaran adalah proses interaksi peserta didik dengan pendidik dan sumber belajar pada suatu lingkungan belajar yang meliputi guru dan siswa yang saling bertukar informasi. Oleh karena itu, pembelajaran harus berjalan dengan baik agar informasi dapat tersampainkan. Pendidik yang berhalangan hadir, akan mengganggu penyampaian materi pembelajaran. Begitu juga bagi peserta didik yang berhalangan hadir tentu akan ketinggalan materi pembelajaran yang diberikan oleh pendidik. Dengan adanya E-Learning memberikan kemudahan dalam proses kegiatan belajar mengajar di sekolah, guru dapat memberikan materi dan tugas dimanapun, siswa mudah untuk mendapatkan materi pembelajaran, dan memudahkan siswa untuk mengerjakan tugas yang telah diberikan oleh guru, tanpa terhalang oleh dimensi ruang dan waktu. Metode pengembangan sistem yang digunakan oleh penulis dalam melakukan penelitian ini adalah metode Prototype. Metode Prototype adalah perangkat lunak prototyping atau siklus hidup menggunakan prototyping. Salah satu metode siklus hidup sistem yang didasarkan pada konsep model bekerja. Dimana pengembang sistem dan klien dapat melihat dan melakukan eksperimen sejak awal proses pengembangan. Dalam metode Prototype terdapat tiga tahap (3) siklus pengembangan, yakni: Fase Pengumpulan Kebutuhan, Fase Membangun Prototype, dan Fase Uji Coba.
\end{abstract}

Kata Kunci: Aplikasi; E-Learning; Materi; Tugas; Prototipe

\section{Pendahuluan}

Perkembangan teknologi sangat berpengaruh terhadap cara bagaimana manusia belajar. Pada era ini manusia memiliki motivasi yang tinggi untuk belajar, sehingga banyak waktu mereka dimanfaatkan untuk mendapatkan ilmu. Semakin cepat manusia belajar dan semakin banyak hal yang dipelajari olehnya, menjadikan manusia kaya akan pengalaman belajar. Semakin banyak pengalaman dalam belajar, semakin terbuka kesempatannya untuk meningkatkan taraf hidup. Peningkatan tersebut membuat munculnya berbagai inovasi yang memudahkan manusia untuk belajar. Inovasi dalam dunia pendidikan dan pembelajaran di era ini telah banyak melibatkan teknologi elektronik. Di era ini, orang yang lebih cepat menerima informasi akan menjadi pemenang. Untuk itu sistem pembelajaran mengharuskan 
penyebaran informasi dengan luas dan cepat, agar pesan pembelajaran didapatkan dengan cepat dan akurat (Wahyuningsih \& Makmur, 2017).

SMP Negeri 7 Kota Tangerang Selatan yang terletak di jalan Cicentang Pulo, kelurahan Rawabuntu, kecamatan Serpong. Dalam proses pembelajaran sendiri SMPN 7 Kota Tangerang Selatan masih dalam pembelajaran tradisional yang dilaksanakan dengan sistem tatap muka dan belum menerapkan semaksimal mungkin pemanfaatan teknologi informasi. Di mana pertemuan peserta didik dan pendidik hanya dalam waktu dan tepat yang sama untuk melaksanakan proses pembelajaran. Interaksi antara peserta didik dan pendidik terjadi secara langsung. Pemberian materi pembelajaran dan tugas pekerjaan rumah hanya pada waktu dan tempat yang sama.

Dengan proses pembelajaran yang masih tradisional dan belum diterapkannya pemanfaatan teknologi secara maksimal pada SMPN 7 Kota Tangerang Selatan, interaksi pembelajaran hanya terjadi di sekolah dengan sistem tatap muka. Ketika pendidik berhalangan hadir, maka penyampaian materi pembelajaran akan terganggu. Begitu juga bagi peserta didik yang berhalangan hadir tentu akan ketinggalan materi pembelajaran yang diberikan oleh pendidik, yang akan berdampak kepada pemahaman materi yang kurang maksimal.

Saat ini dalam dunia pendidikan banyak memanfaatkan penggunaan e-learning untuk memperlancar proses pembelajaran. E-Learning adalah proses pembelajaran online dengan menggunakan ICT. Sistem e-learning dibangun dengan unsur-unsur yang sama dengan membangun teknologi informasi atau komputer. Dengan unsur-unsur tersebut sistem e-learning dapat berjalan dengan baik sehingga dapat mendukung proses pembelajaran (Shadek \& Swastika, 2017). Penggunaan e-learning memberi dampak positif terhadap proses pembelajaran. Adanya e-learning dapat memberi kemudahan pada pendidik dan peserta didik, peserta didik dapat mendapatkan materi pembelajaran dan tugas pekerjaan rumah tidak hanya dalam waktu dan tempat yang sama, dan adanya ruang belajar untuk mendiskusikan materi pembelajaran antara peserta didik dan pendidik di luar jam sekolah. Jika hal ini dapat dimanfaatkan, maka dapat memberikan manfaat besar bagi SMPN 7 Kota Tangerang Selatan dari segi sistem pendidikannya, utamanya kualitas yang dihasilkan dari proses pembelajaran.

Ada beberapa model pengembangan sistem yang dapat digunakan dalam pembuatan e-learning ini yaitu model Waterfall, model Rapid Application Development (RAD), model Spiral, dan model
Prototype. Model pengembangan sistem yang digunakan untuk pembuatan aplikasi e-learning ini adalah model Prototype untuk menggali dan menjabarkan spesifikasi kebutuhan pelanggan secara lebih detail sehingga sesuai dengan kebutuhan pelanggan.

\section{Metodologi}

\subsection{Kajian Teori}

Pertama, penelitian yang dilakukan Suharyanto dan Mailangkay (Suharyanto \& Mailangkay, 2016) menyatakan bahwa permasalahan yang terjadi adalah pendidikan yang hanya dibatasi pada pertemuan di tempat saja, tidak dapat mengembangkan kemampuan dan pengetahuan yang dimiliki oleh para peserta didik. Waktu yang tersedia bagi pendidik dan peserta didik di ruang kelas sangat terbatas. Proses penyampaian materi hanya dilakukan di dalam ruang kelas yang menyebabkan penyampaian materi bisa terlambat atau bahkan tidak tersampaikan jika pertemuan tidak terjadi. Hal tersebut dapat membuat pemahaman peserta didik menjadi terhambat. Untuk mengatasi permasalahan tersebut maka dibuatlah suatu aplikasi E-Learning. Hasil penelitian yang didapat yaitu E-learning berpengaruh positif dan sangat penting terhadap mutu belajar peserta didik. Semakin intensif $e$ learning dimanfaatkan, maka mutu belajar peserta didik akan semakin meningkat.

Kedua, Penelitian yang dilakukan Nanang Nuryadi (Nuryadi, 2018) menyatakan bahwa permasalahan yang terjadi adalah pembelajaran masih menggunakan cara yang biasa, untuk kegiatan belajar mengajar tentu cara itu kurang maksimal karena masih terbatasnya informasi yang dapat diakses oleh siswa. Metode yang digunakan dalam penelitian ini adalah metode pengumpulan data dan metode pengembangan sistem waterfall karena merupakan model pengembangan sistem yang paling mudah dan paling sering digunakan. Hasil penelitian yang didapat yaitu dengan adanya website e-learning ini dapat diakses dari mana saja dan kapan saja melalui jaringan internet. Membantu pihak sekolah khususnya guru dalam kegiatan belajar mengajar. Mempermudah siswa untuk mengakses mata pelajaran dan juga informasi lainnya.

Ketiga, penelitian yang dilakukan oleh Hanum (Hanum, 2013) menyatakan bahwa permasalahan yang terjadi adalah pembelajaran yang terjadi mempunyai waktu belajar praktek yang lebih tinggi dibanding waktu belajar teori di dalam kelas. Penelitian ini merupakan penelitian evaluasi dengan model discrepancy. Evaluasi 
model discrepancy merupakan evaluasi kesenjangan program, melihat kesenjangan program yang terjadi antara yang diharapkan dengan pelaksanaan program. Hasil penelitian yang didapat yaitu dengan teknologi e-learning dapat meningkatkan pemahaman materi bagi siswa, menambah aktivitas belajar, serta membantu guru mengefisiensikan waktu pembelajaran di dalam kelas.

Keempat, penelitian yang dilakukan oleh Susanto, $d k k$ (Susanto \& Astuti, 2017) menyatakan bahwa permasalahan yang terjadi adalah proses pembelajaran sangat terbatas untuk satu pelajarannya hanya berkisar 1-2 jam. Interaksi antara pendidik dan peserta didik kurang interaktif. Sehingga peserta didik akan kesulitan memahami materi secara ulang dengan bertanya kepada pendidik. Metode yang digunakan dalam penelitian ini adalah metode pengumpulan data dan metode pengembangan sistem Waterfall. Hasil penelitian yang didapat yaitu dengan pembelajaran e-learning dapat mendukung proses pembelajaran yang dapat terjadi di mana saja dan kapan saja.

\subsection{Model Pengembangan Prototype}

Pengembangan perangkat lunak dengan menggunakan metode Prototype meliputi aktifitasaktifitas sebagai berikut (Sukamto \& Shalahuddin, 2018):

a. Mendefinisikan Kebutuhan

User dan Programmer bersama-sama mendefinisikan kebutuhan dari perangkat lunak yang akan dibangun.

b. Membuat/Mengubah Prototype

Membuat/mengubah prototype system dengan membuat perancangan yang berpusat pada kebutuhan user yang sudah didefinisikan. Dibuat sesuai dengan kebutuhan sistem yang telah didefinisikan sebelumnya dengan user.

c. Uji Coba Prototype

Uji coba ini dilakukan oleh pengguna untuk mengevaluasi apakah prototipe yang sudah dibuat sudah sesuai dengan keinginan user. Jika sudah sesuai maka perangkat lunak sudah siap untuk digunakan. Jika belum sesuai, maka prototype diperbaiki dengan mendengarkan keluhan dari pengguna untuk memperbaiki prototipe yang sebelumnya.

Kelebihan dari model prototipe yaitu dapat menjelaskan kebutuhan pelanggan secara lebih detail karena pelanggan sering kali kesulitan menyampaikan keinginannya secara detail.

Kelemahan dari model prototipe yaitu user dapat sering mengubah-ubah spesifikasi kebutuhan sistem. Hal ini dapat menyebabkan kualitas perangkat lunak yang kurang baik atau menyebabkan pengulangan tanpa akhir.

\section{Perancangan \\ Use Case Diagram}

Perancangan sistem usulan dibuat menggunakan diagram UML (Unified Modeling Language). Dipilih menggunakan UML karena merupakan bahasa pemodelan visual yang memungkinkan pengembang aplikasi/sistem membuat cetak biru dari sistem yang akan dikembangkan sesuai visi dalam bentuk yang baku, dan dapat dimengerti oleh semua stakeholder karena mencakup berbagai sudut pandang dan dilengkapi dengan mekanisme yang efektif untuk mengkomunikasikan rancangan (Munawar, 2018).

UML memiliki banyak diagram dengan berbagai fungsi dan sudut pandang. Diagram yang umum digunakan di antaranya Use Case Diagram dan Activity Diagram (Sukamto \& Shalahuddin, 2018). Rancangan secara garis besar dari aplikasi e-learning dibuat menggunakan use case diagram yang ditunjukkan pada Gambar 1.

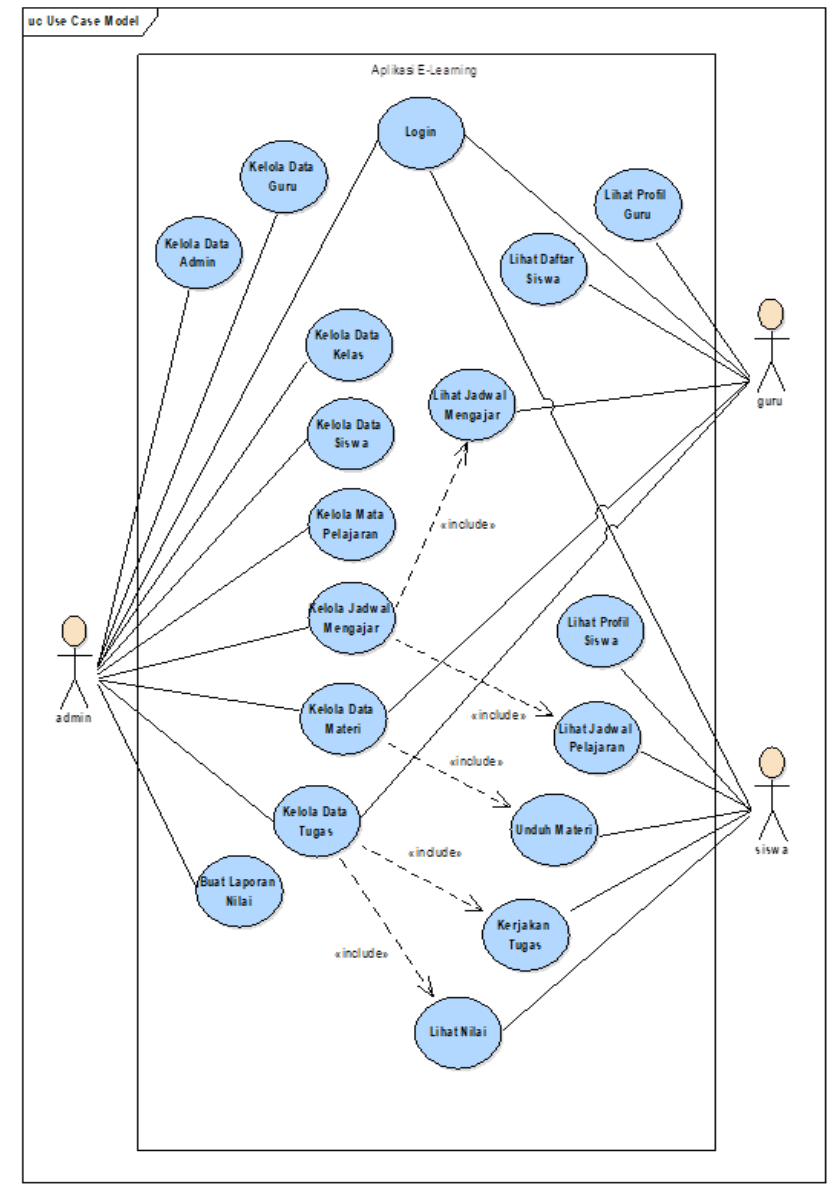

Gambar 1 Use Case Diagram Aplikasi ELearning 
Keterangan gambar:

a. Use Case: Login; Actor: Admin, Guru, Siswa; Deskripsi: Admin atau Guru mengisi username dan password pada form login lalu menekan tombol login agar dapat mengelola data-data e-learning. Siswa mengisi username dan password pada form login lalu menekan tombol login agar dapat mengunduh materi dan mengerjakan tugas.

b. Use Case: Kelola Materi; Actor: Admin, Guru; Deskripsi: Berisi halaman untuk mengelola data materi. Admin atau guru dapat mengunggah file materi.

c. Use Case: Kerjakan Tugas; Actor: Siswa; Deskripsi: Berisi halaman siswa untuk mengerjakan tugas. Siswa dapat menjawab soal-soal yang telah disediakan lalu menekan tombol simpan untuk mengakhiri form mengerjakan tugas.

\section{Activity Diagram}

Activity diagram adalah bagian penting dari UML yang menggambarkan aspek dinamis dari sistem. Activity diagram menggambarkan workflow (aliran kerja) atau aktivitas dalam sebuah use case (Munawar, 2018). Beberapa activity diagram dari aplikasi $e$-learning ditunjukkan pada Gambar 2, 3 dan 4.

Pada Gambar 2 merupakan activity diagram login. Admin, guru, atau siswa memilih menu login pada halaman utama lalu sistem menampilkan form login. Lalu mengisi field username dan password. Sistem memvalidasi data, jika valid, tampil halaman dashboard. Jika data tidak valid, sistem menampilkan pesan error pada form login.

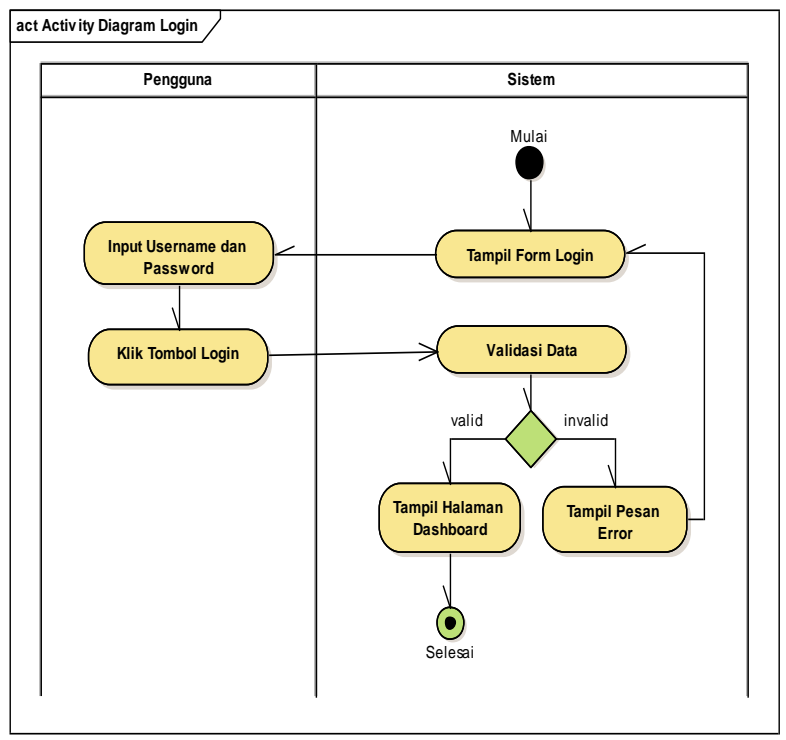

Gambar 2 Activity Diagram Login
Pada Gambar 3 merupakan activity diagram kelola materi. Pada halaman utama, admin atau guru memilih menu materi, lalu sistem menampilkan halaman daftar materi. Pada halaman ini admin atau guru dapat melakukan tambah, ubah, hapus, dan simpan materi.

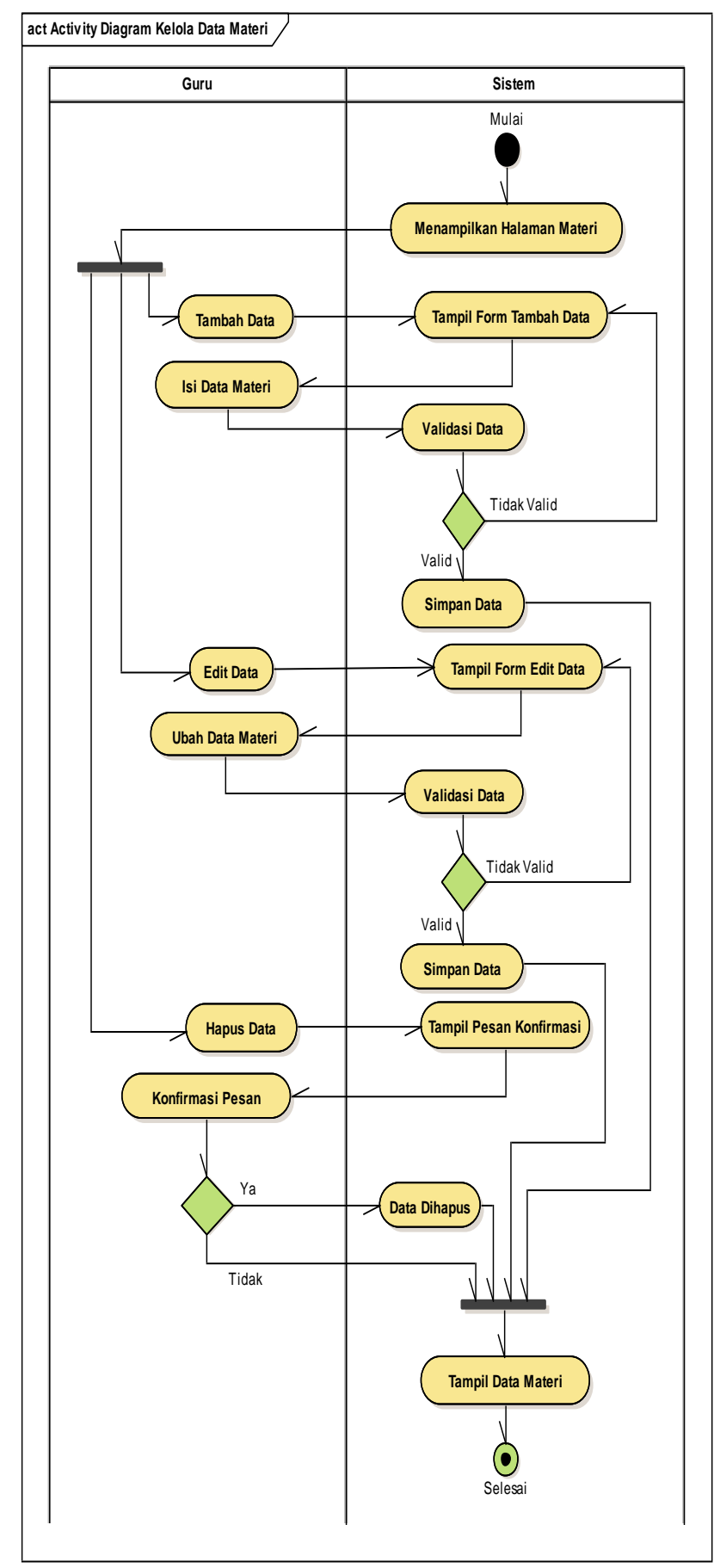

Gambar 3 Activity Diagram Kelola Materi

Pada Gambar 4 merupakan activity diagram kerjakan tugas. Pada halaman utama, siswa memilih menu tugas, lalu sistem menampilkan halaman daftar pelajaran yang memiliki tugas. Pada halaman ini siswa memilih lihat tugas dan 
sistem menampilkan daftar tugas yang terdapat dalam mata pelajaran. Pada halaman ini siswa memilih kerjakan tugas lalu sistem menampilkan informasi sebelum mengerjakna tugas. Lalu siswa memilih mulai mengerjakan tugas. Sistem menampilkan form jawab soal. Pada halaman ini siswa dapat menjawab atau mengisi tugas yang telah diberikan. Setelah itu memilih simpan dan sistem akan menyimpan jawaban siswa.

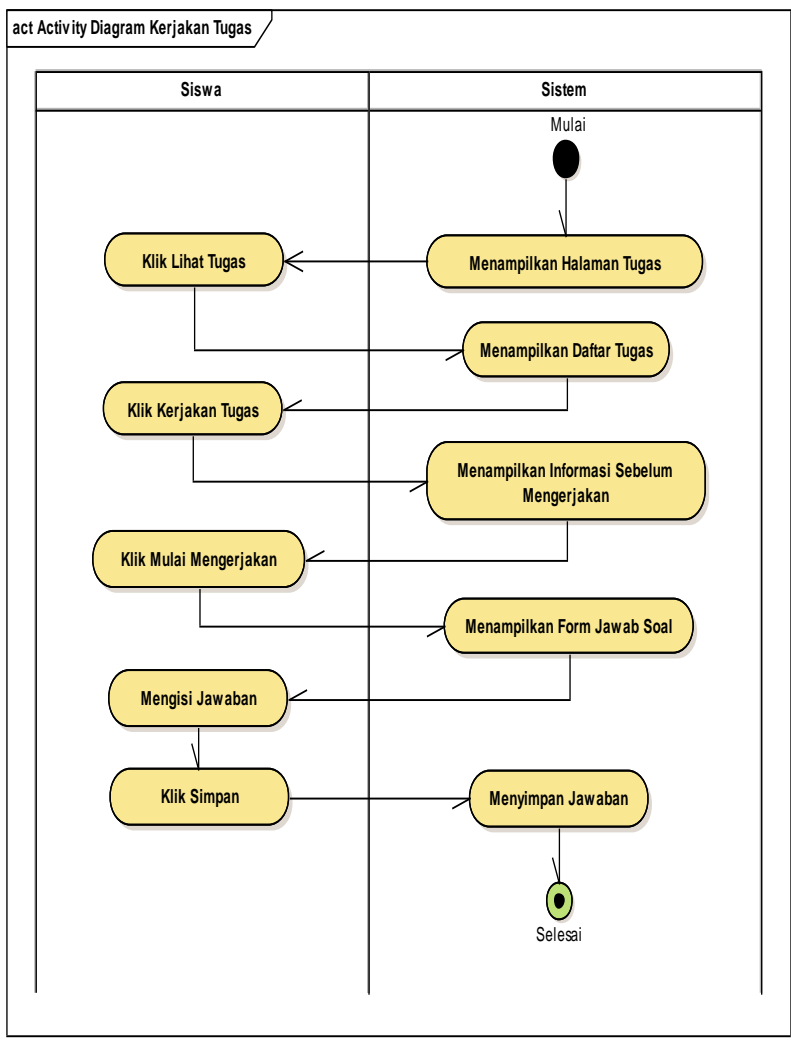

Gambar 4 Activity Diagram Kerjakan Tugas

\section{Implementasi dan Pengujian}

\subsection{Perangkat Pendukung}

Perangkat keras (hardware) yang digunakan dalam pengembangan sistem adalah sebagai berikut:

- Processor Intel® Xeon® CPU E31220@ $3.10 \mathrm{GHz}$

- RAM 8 GB

- Harddisk $1 \mathrm{~TB}$

- VGA 1 GB

Sedangkan perangkat lunak (software) yang digunakan adalah sebagai berikut:

- Sistem Operasi Windows ${ }^{\circledR}$ Server 2012

- Web Server XAMPP for Windows Version 3.2.2

- Browser menggunakan aplikasi Google Chrome

\subsection{Implementasi}

Tahap selanjutnya adalah menerjemahkan spesifikasi sistem yang telah didefinisikan ke dalam bahasa pemrograman yang dapat dimengerti dan dieksekusi oleh computer disebut tahap implementasi (Sommerville, 2011). Implementasi juga dapat diartikan sebagai proses mengkonversi suatu model system menjadi kode sumber (source code) atau program yang dapat dimengerti dan dieksekusi (Stephens, 2015). Dari pengertian tersebut, implementasi adalah tahap menerjemahkan rancangan sistem yang dibuat ke dalam source code menjadi sebuah aplikasi atau program yang dapat dieksekusi.

Dari perancangan yang sudah dilakukan dari implementasi model yang diterapkan ke dalam model sistem, diimplementasikan dalam bentuk program komputer sesuai dengan desain aplikasi yang telah dibuat sebelumnya. Bahasa yang digunakan untuk implementasi adalah bahasa PHP, sedangkan untuk menyimpan dan mengelola data digunakan MySQL. Aplikasi yang dihasilkan dapat dilihat pada Gambar 5, 6, 7, dan 8 .

Pada Gambar 5 adalah tampilan halaman utama. Halaman ini merupakan halaman yang tampil pertama kali ketika aplikasi diakses.

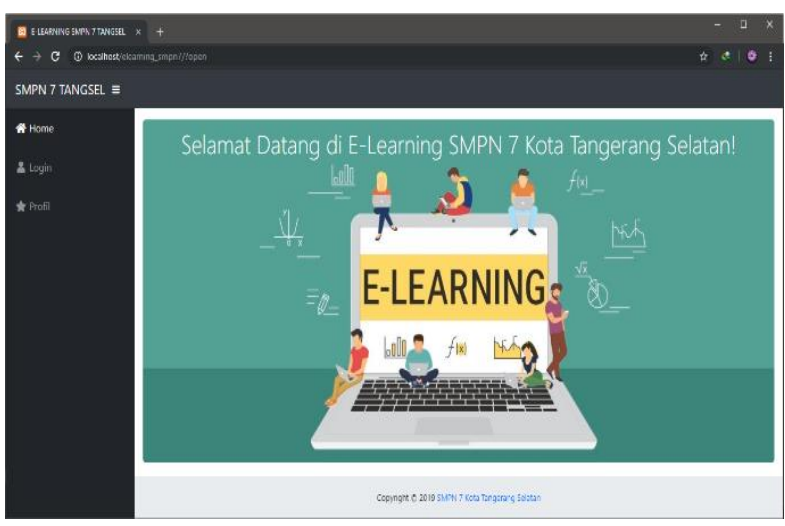

Gambar 5 Tampilan Halaman Utama

Pada Gambar 6 adalah tampilan halaman login merupakan halaman yang muncul ketika pengguna memilih menu login. Halaman ini berisi field username dan field password. Pengguna (admin, guru, siswa) diwajibkan mengisi username dan password atau melakukan login dahulu sebelum masuk ke halaman dashboard. 


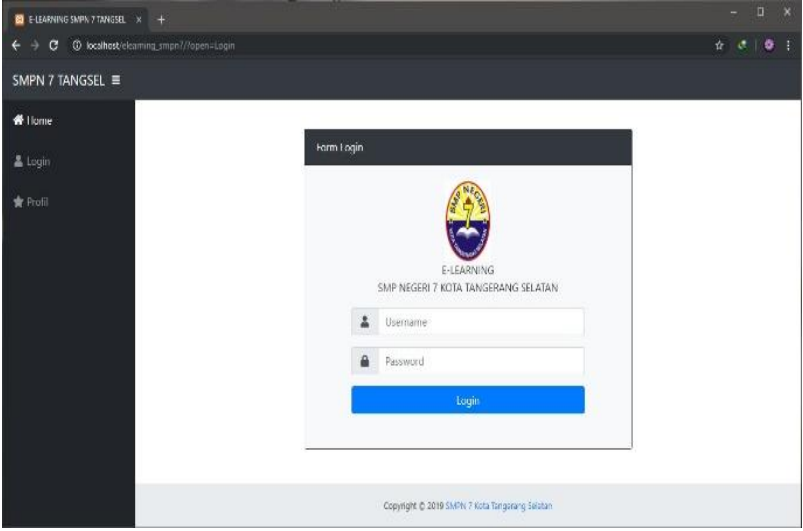

Gambar 6 Tampilan Halaman Login

Pada Gambar 7 adalah tampilan halaman materi merupakan halaman untuk mengelola data materi. Terdapat tombol tambah materi yang berfungsi untuk menambahkan data materi. Tiap baris pada tabel memiliki tombol edit dan delete yang masing-masing berfungsi untuk mengubah dan menghapus data.

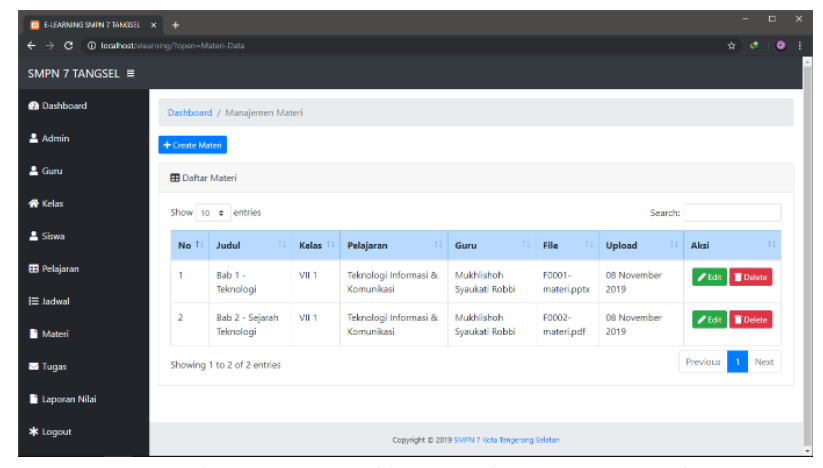

Gambar 7 Tampilan Halaman Materi

Pada Gambar 8 adalah tampilan halaman kerjakan tugas. Halaman ini merupakan halaman siswa untuk mengerjakan tugas.

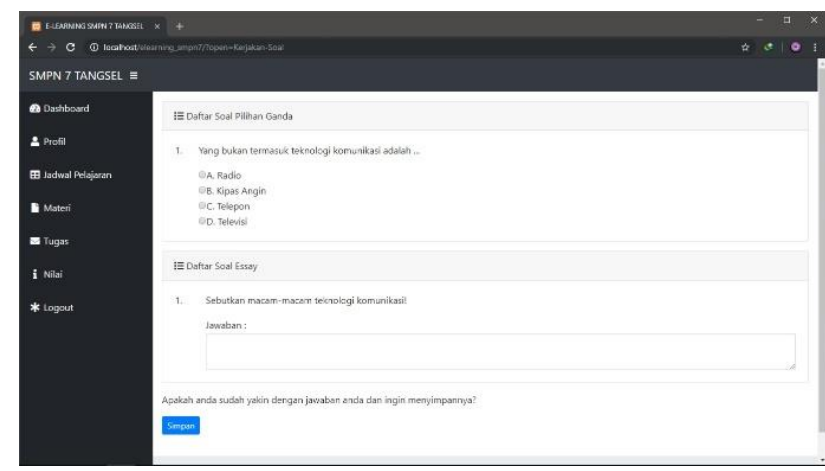

Gambar 8 Tampilan Halaman Kerjakan Tugas

\subsection{Pengujian}

Pada aplikasi e-learning ini dilakukan pengujian koesioner terhadap 21 responden yang terdiri dari 5 guru dan 16 siswa pada SMP Negeri 7
Kota Tangerang Selatan. Pengujian koesioner digunakan untuk melihat tingkat kemudahan pengguna dalam berinteraksi dengan aplikasi. Pengujian koesioner dapat dilihat berdasarkan tabel $1,2,3,4$, dan 5 .

Nilai presentasi kemudahan aplikasi dapat dilihat pada tabel 1. Di mana tabel 1 mempresentasikan nilai dari kemudahan aplikasi.

Tabel 1 Nilai Presentasi Kemudahan Aplikasi

\begin{tabular}{|c|c|c|c|c|c|c|}
\hline \multicolumn{7}{|c|}{ Nilai Presentasi Kemudahan Aplikasi } \\
\hline Pertanyaan & SS & S & RG & TS & STS & Frekuensi \\
\hline 1 & 8 & 13 & 0 & 0 & 0 & 21 \\
\hline 3 & 1 & 17 & 3 & 0 & 0 & 21 \\
\hline 8 & 10 & 10 & 1 & 0 & 0 & 21 \\
\hline 9 & 10 & 10 & 1 & 0 & 0 & 21 \\
\hline Total & 29 & 50 & 5 & 0 & 0 & 84 \\
\hline Presentasi & $34.53 \%$ & $59.52 \%$ & $5.95 \%$ & $0 \%$ & $0 \%$ & $100.00 \%$ \\
\hline
\end{tabular}

Nilai presentasi efektivitas aplikasi dapat dilihat pada tabel 2. Di mana tabel 2 mempresentasikan nilai dari efektivitas aplikasi.

Tabel 2 Nilai Presentasi Efektivitas Aplikasi

\begin{tabular}{|c|c|c|c|c|c|c|}
\hline \multicolumn{7}{|c|}{ Nilai Presentasi Efektivitas Aplikasi } \\
\hline Pertanyaan & SS & S & RG & TS & STS & Frekuensi \\
\hline 1 & 8 & 13 & 0 & 0 & 0 & 21 \\
\hline 2 & 5 & 15 & 1 & 0 & 0 & 21 \\
\hline 6 & 4 & 14 & 3 & 0 & 0 & 21 \\
\hline 7 & 2 & 11 & 8 & 0 & 0 & 21 \\
\hline 9 & 10 & 10 & 1 & 0 & 0 & 21 \\
\hline Total & 29 & 63 & 13 & 0 & 0 & 105 \\
\hline Presentasi & $27.62 \%$ & $60 \%$ & $12.38 \%$ & $0 \%$ & $0 \%$ & $100.00 \%$ \\
\hline
\end{tabular}

Nilai presentasi efisiensi aplikasi dapat dilihat pada tabel 3. Di mana tabel 3 mempresentasikan nilai dari efisiensi aplikasi.

Tabel 3 Nilai Presentasi Efesiensi Aplikasi

\begin{tabular}{|c|c|c|c|c|c|c|}
\hline \multicolumn{7}{|c|}{ Nilai Presentasi Efisiensi Aplikasi } \\
\hline Pertanyaan & SS & S & RG & TS & STS & Frekuensi \\
\hline 4 & 9 & 11 & 1 & 0 & 0 & 21 \\
\hline 5 & 8 & 12 & 1 & 0 & 0 & 21 \\
\hline 10 & 11 & 10 & 0 & 0 & 0 & 21 \\
\hline Total & 28 & 33 & 2 & 0 & 0 & 63 \\
\hline Presentasi & $44.44 \%$ & $52.38 \%$ & $3.18 \%$ & $0 \%$ & $0 \%$ & $100.00 \%$ \\
\hline
\end{tabular}

Nilai presentasi kepuasan aplikasi dapat dilihat pada tabel 4. Di mana tabel 4 mempresentasikan nilai dari kepuasan aplikasi. 
Tabel 4 Nilai Presentasi Kepuasan Aplikasi

\begin{tabular}{|c|c|c|c|c|c|c|}
\hline \multicolumn{7}{|c|}{ Nilai Presentasi Kepuasan Aplikasi } \\
\hline Pertanyaan & SS & S & RG & TS & STS & Frekuensi \\
\hline 3 & 1 & 17 & 3 & 0 & 0 & 21 \\
\hline 9 & 10 & 10 & 1 & 0 & 0 & 21 \\
\hline 10 & 11 & 10 & 0 & 0 & 0 & 21 \\
\hline Total & 22 & 37 & 4 & 0 & 0 & 63 \\
\hline Presentasi & $34.92 \%$ & $58.73 \%$ & $6.35 \%$ & $0 \%$ & $0 \%$ & $100.00 \%$ \\
\hline
\end{tabular}

Nilai presentasi semua kriteria aplikasi adalah presentasi gabungan dari penilaian seluruh kategori berdasarkan kriteria sebelumnya. Dapat dilihat pada tabel 5, di mana mempresentasikan nilai dari semua kriteria aplikasi.

Tabel 5 Nilai Presentasi Semua Kriteria

\begin{tabular}{|c|c|c|}
\hline Kriteria & Frekuensi & Persentase \\
\hline Sangat Setuju & 68 & $32.38 \%$ \\
\hline Setuju & 123 & $58.57 \%$ \\
\hline Ragu-ragu & 19 & $9.05 \%$ \\
\hline Tidak Setuju & 0 & $0 \%$ \\
\hline Sangat Tidak Setuju & 0 & $0 \%$ \\
\hline Total & 210 & $100.00 \%$ \\
\hline
\end{tabular}

\section{Kesimpulan}

Berdasarkan penulisan dan penelitian yang telah diuraikan, mengenai perancangan aplikasi $e$ learning SMP Negeri 7 Kota Tangerang Selatan, maka dapat disimpulkan sebagai berikut:

a. Aplikasi e-learning berbasis website ini membuat proses belajar mengajar tetap berlangsung saat di luar jam sekolah. Berdasarkan pengamatan koesioner dilapangan, aplikasi e-learning ini nilai setujunya adalah $58.57 \%$ dimana frekuensi yang diterima adalah 123 dari 210 , dan nilai sangat setujunya adalah $32.38 \%$ dimana frekuensi yang diterima adalah 68 dari 210 .

b. Aplikasi ini membantu pendidik untuk mendistribusikan materi pelajaran saat berhalangan hadir di jam sekolah. Berdasarkan pengamatan koesioner dilapangan, nilai efesiensi aplikasi e-learning ini setujunya adalah $52.38 \%$ dimana frekuensi yang diterima adalah 33 dari 63 .

c. Aplikasi e-learning ini memudahkan peserta didik yang ketinggalan materi karena berhalangan hadir di sekolah. Berdasarkan pengamatan koesioner dilapangan, nilai kemudahan aplikasi e-learning ini setujunya adalah $59.52 \%$ dimana frekuensi yang diterima adalah 50 dari 84 .

\section{Saran}

Berdasarkan hasil perancangan aplikasi ini, diberikan beberapa saran yang dapat membantu pengembang aplikasi ini, guna untuk memperoleh hasil yang lebih baik dan dapat bermanfaat bagi semua. Adapun saran yang diajukan yaitu:

a. Aplikasi diharapkan dapat dilengkapi dengan fitur chat, kolom diskusi untuk memudahkan interaksi antara pendidik dan peserta didik.

b. Diharapkan dapat mendukung fitur video, untuk memudahkan pemahaman materi belajar pada peserta didik.

c. Aplikasi dikembangkan agar bisa berjalan di berbagai platform seperti mobile web, apk android, apk iOs dan berbagai platform lainnya.

\section{Referensi}

Hanum, N. S. (2013). The Effectiveness Of E-Learning As Instructional Media (Evaluation Study Of E-Learning Instructional Model INSMK Telkom Sandhy Putra Purwokerto). Jurnal Pendidikan Vokasi, Vol 3, Nomor 1, 92.

Munawar. (2018). Analisis Perancangan Sistem Berorientasi Objek dengan UML (Unified Modeling Language). Bandung: Informatika Bandung.

Nuryadi, N. (2018). Rancang Bangun Aplikasi Website E-Learning Pada SMK Respati 1 Jakarta. Jurnal Teknik Komputer Vol 4, No. 1, 162.

Shadek, T. F., \& Swastika, R. (2017). Pengembangan Aplikasi Sistem E-Learning Pada Seluruh Mata Kuliah Dengan Menggunakan Program Hypertext Prepocessor (Php) Dalam Rangka Peningkatan Mutu Proses Dan Hasil Pembelajaran. Jurnal ProTekInfo Vol. 4, 13.

Sommerville, I. (2011). Software Engineering (9th ed.). Boston: Addison-Wesley.

Stephens, R. (2015). Beginning Software Engineering. Indiana: John Wiley \& Sons, Inc.

Suharyanto, \& Mailangkay, A. B. (2016). Penerapan ELearning Sebagai Alat Bantu Mengajar dalam Dunia Pendidikan. Jurnal Ilmiah Widya Volume 3 Nomor 4, 17.

Sukamto, R. A., \& Shalahuddin, M. (2018). Rekayasa Perangkat Lunak (Revisi). Bandung: Informatika Bandung.

Susanto, W. E., \& Astuti, Y. G. (2017). Perancangan ELearning Berbasis Web Pada SMP Negeri 3 Patuk Gunungkidul Yogyakarta. Jurnal Bianglala Informatika Vol 5 No $2,76$.

Wahyuningsih, D., \& Makmur, R. (2017). E-Learning Teori dan Aplikasi. Bandung: Informatika Bandung. 